\title{
Application of Recommendation System on Semantic based Matching Approach
}

\author{
Jayashree Salunke \\ Department of Information Technology, \\ Pimpri Chinchwad College of Engineering, Pune, \\ India
}

\author{
Anagha Chaudhari \\ Department of Information Technology, \\ Pimpri Chinchwad College of \\ Engineering, Pune, India
}

\begin{abstract}
A recommendation system is a software program which endeavours to limit determinations for clients in light of their communicated inclinations, past behaviour, or other information which can be mined about the client or different clients with similar interests. This paper proposes a new personalized recommendation model or personalized academic knowledge sharing system based on domain knowledge to emphasize the importance of domain knowledge in recommendation process. We explore user profiling within recommender systems, working on the problem of recommending academic users or employees to share his/her knowledge. We propose a one of a kind semantic based matching approach to portray the similarity of academic employees to share and improve his/her knowledge. This system recommends the persons who have deep knowledge of the domain and research interest appropriately as compare to other state of art system. We used here text mining for extract the research interest..
\end{abstract}

\section{General Terms}

Collaborative filtering, Content based filtering, Hybrid recommendation Algorithm

\section{Keywords}

Academic knowledge sharing system, Recommendation System,Semantic based Matching Approach, Text Mining..

\section{INTRODUCTION}

Knowledge management is an emerging field that has commanded attention and support from the industrial community. Many organizations currently engage in knowledge management in order to leverage knowledge both within their organization and externally to their shareholders and customers Knowledge management involves the creation of value from an organization's intangible assets. Alavi and Leidner $w 3 x$ indicate that many organizations are developing information systems designed specifically to facilitate the sharing and integration of knowledge. Two key concerns for knowledge management arise from this approach. First, knowledge management encompasses much more than technologies for facilitating knowledge sharing. In fact, practitioners are beginning to realize that people and the culture of the workplace are the driving factors that ultimately determine the success or failure of knowledge management initiatives w10,44x. Second, emphasis on technology forces a narrow view that may inhibit the growth and staying power of knowledge management [5].

Knowledge management is a young discipline for which a codified, generally accepted framework has not been established w9x. Despite this fact, a variety of approaches to knowledge management have been implemented across a variety of organizations. However, these approaches do not adequately fulfill the knowledge management needs of organizations. There is concern that knowledge management may simply be a passing fad - similar to business process reengineering ŽBPR. and the generally accepted notion that it has failed w11,16x. Liebowitz w32x and Liebowitz and Beckman w34x observe that knowledge management must be integrated within the strategic goals of the organization in order to fully realize its potential for enhancing organization performance [5].

\section{RECOMMENDATION SYSTEM}

Recommendation systems have received significant attention from both academia and industry since the mid-1990s when collaborative filtering was introduced. Recommendation systems are usually classified into two categories: contentbased recommendations and collaborative filtering based recommendations $[8,15]$.

Content-based filtering recommends items that are similar to ones, the active user preferred in the past. Content-based recommendation systems recommend an item to a user based on item description and user's interests and are useful recommending web pages, news articles, items for Sale, etc $[8,15]$.

Traditional collaborative filtering recommends items to an active that have been rated highly by users who are similar to the active user. Collaborative filtering based systems recommend items that other similar users have preferred.

Collaborative recommendation computes the similarity to other users rather than to other items. Several hybrid recommendation systems combine both collaborative and content-based methods $[8,15]$.

\section{STATE OF ART}

Current active user is hunting down the client for enhance his/her knowledge, who had information on a similar research interest.Our Semantic based Matching Approach Recommendation System prescribed the client whose exploration intrigue is same and who had profound learning about a similar research interest.User is suggested who distributed journal more,whose patent,workshop,books are more on a similar research premium.

\subsection{Problem Statement}

Application of Recommendation System on Semantic based Matching Approach

\subsection{Objective Of The Work}

1. To achieve a semantic-based matching approach personalized academic knowledge sharing system Knowledgeable user recommendation.

2. To achieve fine grained control. 
4. LITERATURE SURVEY

Table 1. Literature Survey Table

\begin{tabular}{|c|c|c|c|c|}
\hline $\mathbf{S}$ & Paper Title & Author Nan & $\begin{array}{l}\text { Publication } \\
\text { Details }\end{array}$ & Contribution \\
\hline 1 & $\begin{array}{l}\text { Potential Friend } \\
\text { Recommendati } \\
\text { on in Online } \\
\text { Social } \\
\text { Network }\end{array}$ & Xing Xie & IEEE & $\begin{array}{l}\text { Context } \\
\text { Content \& } \\
\text { Domain } \\
\text { Knowledge }\end{array}$ \\
\hline 2 & $\begin{array}{l}\text { Recommender } \\
\text { systems for } \\
\text { personal } \\
\text { knowledge } \\
\text { management } \\
\text { in collaborative } \\
\text { environments }\end{array}$ & $\begin{array}{l}\text { Lu Zhen } \\
\text { Hai-Tao Son } \\
\text { Jun-Tao He }\end{array}$ & ELSEVIER & $\begin{array}{l}\text { Personal } \\
\text { Knowledge } \\
\text { management }\end{array}$ \\
\hline 3 & $\begin{array}{l}\text { Intelligent } \\
\text { Services: A } \\
\text { Semantic } \\
\text { Recommender } \\
\text { System for } \\
\text { Knowledge } \\
\text { Representation } \\
\text { in Industry }\end{array}$ & $\begin{array}{l}\text { Mahsa } \\
\text { Mehrpoor, } \\
\text { Andreas } \\
\text { Gjærde, } \\
\text { Ole Ivar } \\
\text { Sivertsen }\end{array}$ & IEEE & $\begin{array}{l}\text { Ontology } \\
\text { based } \\
\text { recommend } \\
\text { der } \\
\text { system }\end{array}$ \\
\hline 4 & $\begin{array}{l}\text { User } \\
\text { Recommender } \\
\text { System Based } \\
\text { on Knowledge, } \\
\text { Availability and } \\
\text { Reputation } \\
\text { from } \\
\text { Interactions in } \\
\text { Forums }\end{array}$ & $\begin{array}{l}\text { Silvana V. } \\
\text { Aciar, } \\
\text { Gabriela I. } \\
\text { Aciar, } \\
\text { Cesar. A. } \\
\text { Collazos, } \\
\text { and Carina } \\
\text { S. } \\
\text { González }\end{array}$ & IEEE & $\begin{array}{l}\text { Knowledge } \\
\text {,availability } \\
\text { and } \\
\text { reputation } \\
\text { of user }\end{array}$ \\
\hline 5 & $\begin{array}{l}\text { A systems } \\
\text { thinking } \\
\text { framework for } \\
\text { knowledge } \\
\text { management }\end{array}$ & $\begin{array}{l}\text { B. } \\
\text { Rubenstei } \\
\text { n- } \\
\text { Montano), } \\
\text { J. } \\
\text { Liebowitz } \\
\text { Buchwalte } \\
\text { r , D. } \\
\text { McCaw , } \\
\text { B. } \\
\text { Newman , } \\
\text { K. Rebeck }\end{array}$ & $\begin{array}{l}\text { ELSEVIE } \\
\mathrm{R}\end{array}$ & $\begin{array}{l}\text { Knowledge } \\
\text { Manageme } \\
\text { nt }\end{array}$ \\
\hline
\end{tabular}

In this paper, we have taken 5 papers based on the Application of Recommendation System on Semantic based Matching Approach. The 1st paper is "Potential Friend Recommendation in Online Social Network" Contribution of this paper is Idea of Recommendation System on semantic based coordinating methodology. The second paper is " Recommender systems for personal knowledge management in collaborative environments". Commitment of this paper is close to personal Knowledge management. The third paper is" Intelligent Services: A Semantic Recommender System for Knowledge Representation in Industry". Commitment of this paper is philosophy based recommender framework. The forward paper is "User Recommender System Based on
Knowledge, Availability and Reputation from Interactions in Forums". Commitment of this paper is information accessibility and reputation. The fifth paper is "A systems thinking framework for knowledge management" Contribution of this paper is Knowledge management in huge setting.

\section{PROPOSED SYSTEM}

Figure 1 demonstrates architecture of our framework. We keep up client Research interset history that implies we gather information. By considering gathered information and profile investigation we create similarity metric and ordering client's profile. By getting yield of similarity metric, we finish prescribe client module to current client.

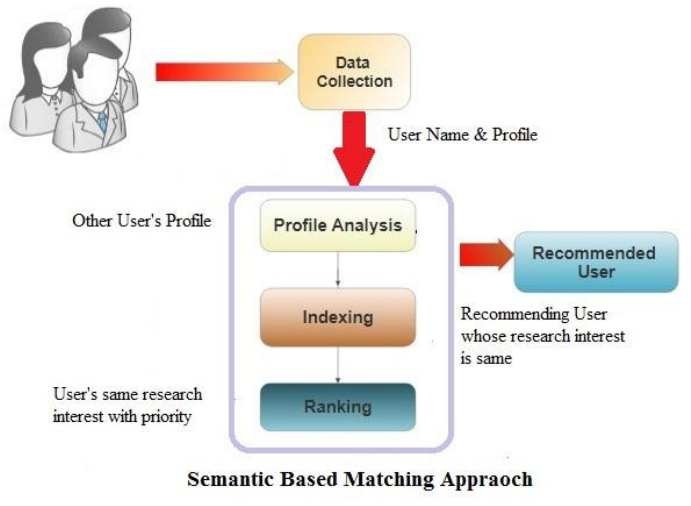

Fig 1: System Architecture of Semantic based Matching Approach

Text Mining is another field that tries to remove important data from common dialect content. It can be characterized as the way toward investigating content to separate data that is helpful for a particular reason. Contrasted and the sort of information put away in databases, content is unstructured, uncertain, and hard to process. All things considered, in current culture, content is the most public route for the formal trade of data. Content mining as a rule manages writings whose capacity is the correspondence of real data or conclusions, and the boosts for attempting to remove data from such content naturally is entrancing - regardless of whether achievement is just fractional. Frequently message mining, otherwise called text/ information mining or content examination, is mistaken for data recovery, the right meaning of text mining is "the way toward getting superb data from content", content mining deals with unstructured data. Essentially, the procedure permits recognizable proof of new and surprising data from an accumulation of content. We used here text mining for extract the research interest from Name of the Journal, patent, books, and workshop.

\section{EXPERIMENTAL RESULTS}

In this project, [Figure-2] shows the home page of proposed system, when the Project is first started it displays this page.

[Figure-3] shows the user login form where users who have already registered can be able to logged-in by using their email as their username and password which they have provided while registration.

[Figure-4] shows the user's profile page system.

[Figure-5] shows the recommended user's page, whose profile is matching on the basis of research interest,user recommended correct user who have same domain same 
research interest and who had published more papers,more books,more workshop,more patent that user means who had deep knowledge of the same research interest that user is recommended to the current active user.

[Figure-6] shows the admin home page.

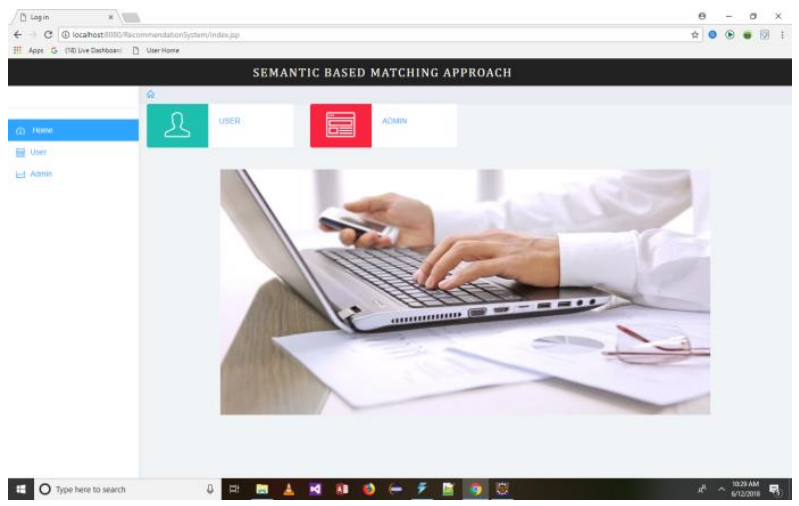

Fig 2: Home Page

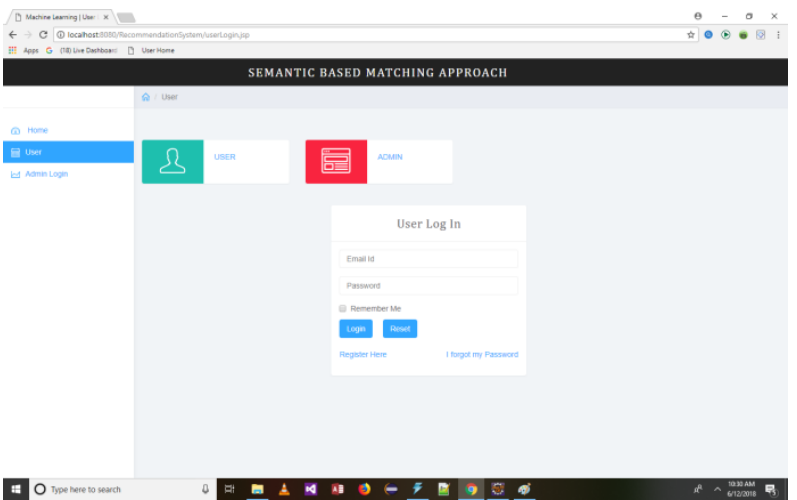

Fig 3: Login Form

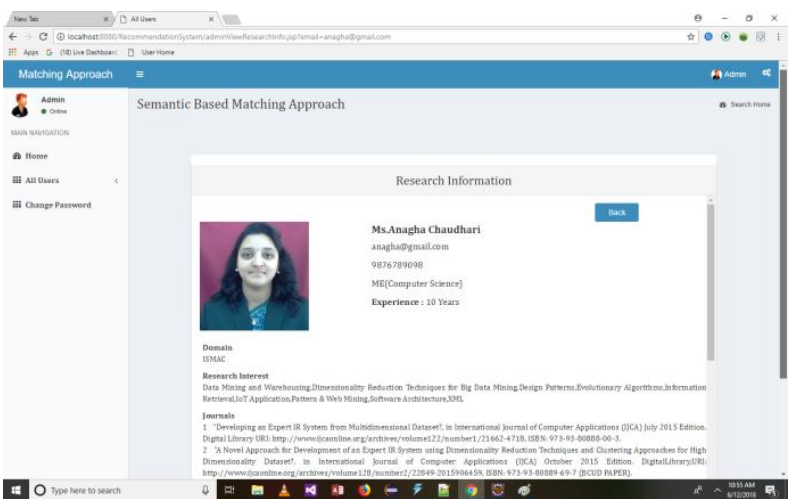

Fig 4: Profile Page

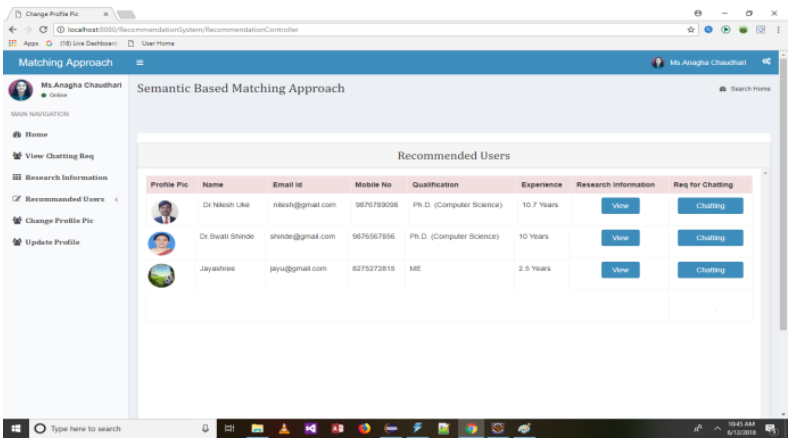

Fig 5: Recommended User's List

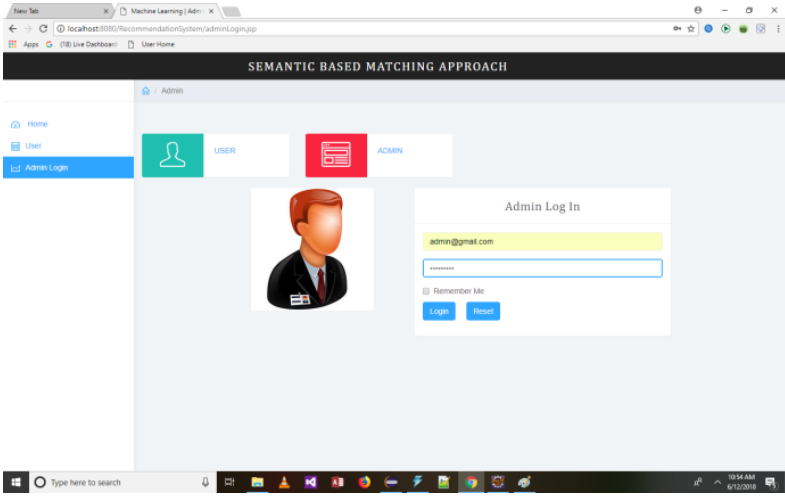

Fig 6: Admin Login page

\section{RESULTS}

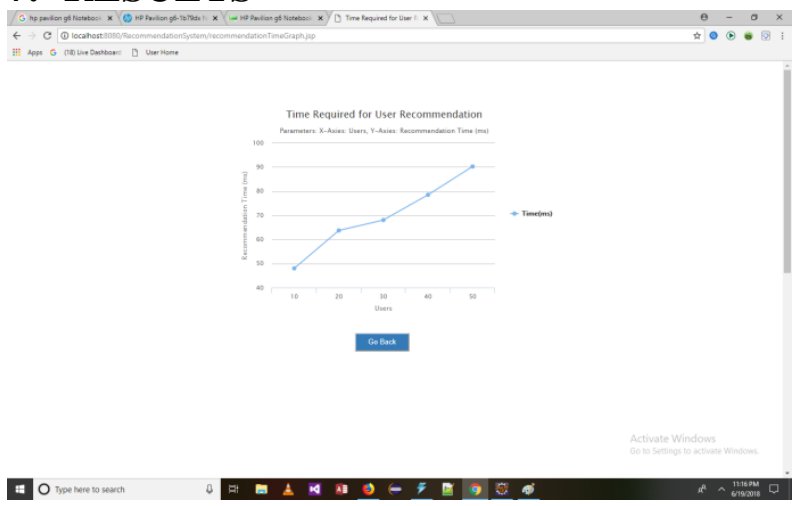

Fig 7: Recommendation Time Graph

The above Figure 7 shows that the graph of recommendation time in milliseconds (ms). The $\mathrm{x}$-axis represents users set and $\mathrm{y}$-axis represents recommendation time in $\mathrm{ms}$.

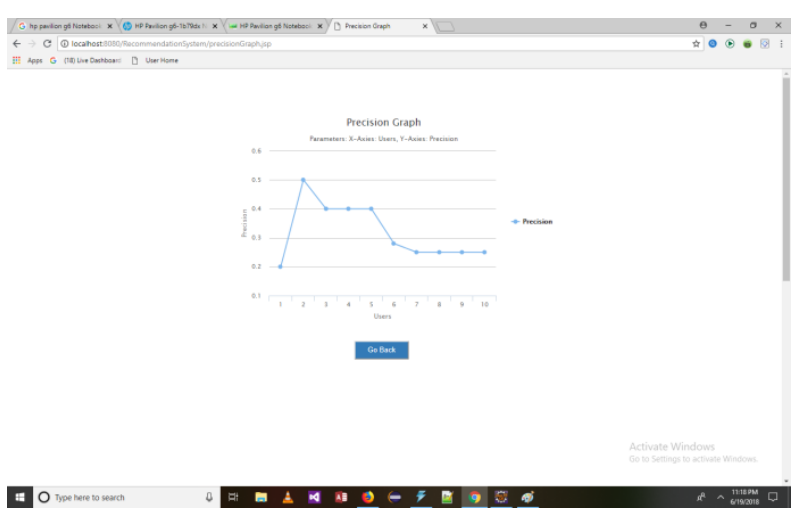

Fig 8: Precision Graph

The above Figure 8 shows that the graph of precision. The $x$ axis represents users and $y$-axis represents precision.

The evaluation was carried out taking into account the successful recommendations over all the recommendations. Successful recommendations are defined as: given a requirement of the user, the recommendation that meets their expectations is considered successful. The evaluation obtained from the user about the recommendations made is used for precision.

Formula for calculating precision.

$$
\text { Precision }=\underline{\mid \text { relevant users }\} \cap\{\text { retrieved users }\} \mid}
$$


Where

Relevant users $=$ top 2 users ie threshold

Retrieved users $=$ recommendation users count

\section{APPLICATIONS}

1. We can make real time applications for recommending personalized academic knowledge sharing system.

2. It provides recommendations for services like travel services, experts for consultation, houses to rent, or matchmaking services.

3. We can make the mobile app for recommending personalized academic knowledge sharing system for sharing his/her knowledge.

\section{CONCLUSIONS}

1. We designed A Semantic based Matching Approach recommendation framework which can characterize user research interest as well as combining domain deep knowledge to improve recommending quality.

2. Hybrid Recommendation Algorithm is used for the Semantic based Matching Approach.

\section{REFERENCES}

[1] Xing Xie,"Potential Friend Recommendation in Online Social Network",IEEE,2010

[2] Lu Zhen, Hai-Tao Song, Jun-Tao He,"Recommender systems for personal knowledge management in collaborative environments", ELSEVIER,2012

[3] Mahsa Mehrpoor, Andreas Gjærde,Ole Ivar Sivertsen,"Intelligent Services: A Semantic Recommender System for Knowledge Representation in Industry",IEEE,2014

[4] Silvana V. Aciar, Gabriela I. Aciar, Cesar. A. Collazos, and Carina S. González,"User Recommender System Based on Knowledge, Availability and Reputation from Interactions in Forums",IEEE,2016

[5] B. Rubenstein-Montano, J. Liebowitz, J. Buchwalter,D. McCaw , B.Newman, K. Rebeck, The Knowledge Management Methodology Team,"A systems thinkin framework for knowledge management", ELSEVIER,2001
[6] Zhibo Wang, Jilong Liao, Qing Cao,Hairong Qi,Senior, and Zhi Wang," Friendbook: A Semantic- Based Friend Recommendation System for Social Networks", IEEE Transactions On Mobile Computing, March 2015

[7] Sachin V Josef, MinuLalitha Madhavu “ Incremental Iterative Time Spent Based Ranking Model For Online Activity based Friend-Group Recommendation Systems",IEEE,2015

[8] Varun Jain D J, Dr. M Siddappa "FriendRecommendation Through Semantic Based Matching And Collaborative Filtering System In Social Networks", International Journal Of Advances In Cloud Computing And Computer Science (IJACCCS), 2015

[9] Jyoti Sharma,Pinky Tanwar.," A Survey on Friend Recommendation System”, IJARIIE, 2016

[10] Harsha Chaudhari, Nilam Darekar, Vishal Raut, Harshal Wani, Prof. Darshika Lothe "Friend book Recommendation System", International Engineering Research Journal (IERJ) ,2016

[11] Dagadu M. Jadhavar , V. R. Chirchi "Friend Recommendation System for Online Social Networks", International Journal of Computer Applications,Nov 2016

[12] Li Bian, Henry Holtzman" Online Friend Recommendation through Personality Matching and Collaborative Filtering", The Fifth International Conference on Mobile Ubiquitous Computing, Systems, Services and Technologies, 2011

[13] Pooja Tasgave1, Amit Dravid "Friendbook: A Lifestyle based Friend Recommendation System", International Journal for Research in Applied Science \& Engineering Technology (IJRASET),2015

[14] Mrs Jayashree B. Salunke, Ms.Anagha N. Chaudhari, ” Classification of Recommendation System for Ecommerce Application", MAT Journals (Computer Science Engineering and Software Testing), Dec 2017.

[15] Mrs Jayashree B. Salunke , Ms.Anagha N. Chaudhari, "Implementation of Friendbook: A Recommendation System for Social Networks", MAT Journals (Web Development and Web Designing), 29 Dec 2017 